\title{
CLIMATE REVERSALS AND THE TRANSITION TO AGRICULTURE
}

\author{
Gregory K. Dow, Clyde G. Reed, and Nancy Olewiler \\ Department of Economics \\ Simon Fraser University
}

July 2008

\begin{abstract}
Until about 13,000 years ago all humans obtained their food through hunting and gathering, but thereafter people in some parts of the world began a transition to agriculture. Recent data strongly implicate climate change as the driving force behind the transition in southwest Asia. We propose a model of this process in which population and technology respond endogenously to climate. After a period of favorable environmental conditions during which regional population grew, an abrupt climate reversal forced people to take refuge at a few favored sites. The resulting spike in local population density reduced the marginal product of labor in foraging and made cultivation attractive. Once cultivation began, technological progress, including artificial selection, eventually led to domesticated plants. Farming became a permanent part of the regional economy when productivity growth was combined with climate recovery. The available data on cases of transition and non-transition are consistent with this model but often inconsistent with rival explanations.
\end{abstract}


Acknowledgment. Doug Allen, Matthew Baker, Ofer Bar-Yosef, Cliff Bekar, Sam Bowles, Sue Colledge, Patrick Francois, Brian Hayden, Hillard Kaplan, Gordon Myers, Arthur Robson, and four anonymous referees for the Journal of Economic Growth commented on earlier drafts. We are grateful to audiences at Simon Fraser University, the University of British Columbia, the 2005 SSHA meeting, the 2006 AEA meeting, the 2006 SFU workshop on the Neolithic transition, and the 2006 Conference on Early Economic Developments at the University of Copenhagen. The Social Sciences and Humanities Research Council of Canada provided financial support. All are absolved of responsibility. 


\section{Introduction}

Anatomically modern humans have existed for almost 200,000 years (McDougall, Brown, and Fleagle, 2005). Judging from the complexity of tool design, cognitively modern humans have probably existed for at least 40,000 years. Yet until about 13,000 years ago, all humans obtained their food exclusively by hunting animals or gathering wild plants. The shift to plant cultivation began at this time in southwest Asia. Convincing evidence of plant domestication exists for ten independent centers of origin (Balter, 2007). This evidence comes from a relatively small number of archaeological sites in southwest Asia, Africa, China, southern India, New Guinea, the Andes, Mesoamerica, and the eastern U.S.A. From these centers, agriculture subsequently diffused to most parts of the globe.

Prior to agriculture, there is little evidence of long run economic progress (Dow and Reed, 2008). The agricultural transition was necessary for the existence of cities, states, and writing, and with few exceptions for specialized crafts, inequality, hierarchy, and organized warfare. Through its effect on population density, agriculture was also a precondition for the industrial revolution and modern economic growth (Kremer, 1993; Becker et al., 1999; Galor and Weil, 2000; Galor, 2005). Indeed, this transition appears to have had long-term consequences for differential growth performance in contemporary economies (Bockstette et al., 2002; Olsson and Hibbs, 2005; Putterman, 2008).

How can one explain the long lag between the evolution of modern humans and the shift to agriculture? Why did cultivation emerge when and where it did? Several authors have recently pointed to climate change as a leading suspect behind the transition. For example, Richerson et al. (2001) assert that agriculture was impossible in the most 
recent Ice Age because prevailing climatic conditions--low temperatures and atmospheric $\mathrm{CO}_{2}$ levels, extreme aridity, and high-amplitude fluctuations on time scales of a decade or less to a millennium--severely limited the expected returns on investments in agriculture. In their view, the relatively warm, wet, and stable conditions after the Ice Age encouraged cultural evolution toward reliance on specialized plant resources, leading eventually to agriculture. The problem with this perspective is that archaeologists have not found evidence for agriculture anywhere in the world during the initial warming phase after the last glacial period, even though this interval lasted almost two millennia.

Warmer conditions indeed led to abundant wild resources, substantial population growth, and a sedentary lifestyle in southwest Asia. This idyllic period was interrupted about 13,000 years ago by an abrupt climate reversal called the Younger Dryas, during which cooler and drier conditions again prevailed. Many hunting and gathering sites became less attractive and the population either returned to a nomadic lifestyle or took refuge in a few areas that remained relatively hospitable. It is only during this harsher period that cultivation is first detected.

Our model accounts for the puzzling fact that a climate reversal was needed to initiate the transition. The key idea is that forcing a large regional population through a small geographic bottleneck led to a spike in labor supply at the best food production sites. Under reasonable technological assumptions there is a population threshold beyond which some labor is optimally allocated to cultivation. The climate reversal in southwest Asia propelled local densities beyond this threshold at a few favorable locations.

If technology had remained constant and the climate deterioration had been permanent, falling living standards would have lowered region-wide population, reducing 
pressure on the best sites. Eventually local densities would have dropped below the minimum needed for cultivation, and farming would have been a temporary expedient on the way back to a foraging lifestyle. However, two factors intervened. Once cultivation began, productivity increased through learning by doing. Moreover, the climate reversal was temporary. After the Younger Dryas ended, temperatures and precipitation rose, the early crop plants spread beyond their previous wild range, population growth resumed, and settled agriculture became the norm.

Southwest Asia provides the most complete data documenting the transition from (a) extensive gathering of wild plants to (b) cultivation to (c) domestication and finally to (d) agricultural societies. 'Domestication' refers to the genetic changes resulting from the practice of cultivation (see Nesbitt, 2002; Tanno and Wilcox, 2006; Weiss et al., 2006; Balter, 2007). Following current practice in archaeology, we use the term 'agriculture' to mean dietary reliance on fully domesticated plants. The overall process from (a) to (d) took many thousands of years. The key transition was the advent of cultivation, and this puzzle provides the focus for the present paper.

Due to the vast scale of the literature, we limit our review to research that treats climate as the prime mover behind the transition to agriculture. Other proposed prime movers have included technology, population, culture, resource depletion, and property rights. For surveys that encompass the full spectrum of approaches, see Pryor (1983, 2004), Locay (1989), and Weisdorf (2005).

One early advocate of a link between climate change and domestication was $\mathrm{V}$. Gordon Childe (1951: 67-72), who argued that reduced precipitation in arid sub-tropical regions forced animals, plants, and humans to retreat to springs and streams where water 
remained available. Childe thought that this process likely led to animal domestication. He believed that plant cultivation had begun earlier, perhaps in river valleys subject to annual flooding (such as the Nile). At one point he remarked: "It is really unprofitable to speculate how, where, and when the cultivation of cereals began.” (1951: 66). Childe clearly had no economic explanation for the origins of plant cultivation. He also lacked accurate data on climate as well as the location and timing of early cultivation and animal domestication. His approach was abandoned for several decades by archaeologists, in part because of these data limitations.

As better data became available, interest in environmental explanations revived. Bar-Yosef and Meadow (1995) argued that cold and dry conditions during the Younger Dryas caused yields from wild cereal stands to decrease in southwest Asia and thus provided incentives for cultivation. Similarly, Hillman et al. (2001) suggested that the Younger Dryas drove foraging populations to cultivate caloric staples. Our analysis grows out of this recent view from archaeology, while providing the requisite theoretical structure and incorporating population and technical change as endogenous variables.

Among economists, Morand (2002) has recently asserted that a climate reversal in southwest Asia caused people to take refuge at locations where water was available. He attributes agriculture mainly to a climate bias that reduced foraging productivity. Morand's formal model focuses on issues of human capital and household bargaining that play no role in our analysis. His model also implies that people choose either foraging or agriculture rather than using a combination of both, as is common during a transition.

Olsson (2001) constructs a model in which several factors could induce a transition to agriculture, including climate changes biased toward agriculture or against 
foraging; an exogenous increase in population; a change in preferences; or exogenous improvements in agricultural productivity as a by-product of foraging. Regarding climate, Olsson favors the view that conditions in southwest Asia deteriorated less for agriculture than for foraging. We depart from Morand and Olsson by dropping the idea that climate change was directly biased in favor of agriculture. Instead, we stress an indirect channel running from climate to migration and labor allocation decisions.

Ashraf and Michalopoulos (2006) have developed yet another explanation that treats climate change as the ultimate driving force. They propose a causal channel from mild climate stress to changes in foraging technique, which led to increasing investments in tools, infrastructure, and habitat clearance. As a result, the latent productivity of agriculture improved until a threshold was crossed and agriculture was adopted.

In our model the proximate trigger for cultivation is not improved technology, but rather a negative climate shock that increases local population density at the best sites and causes reallocation of labor toward cultivation. It is the short run response to the climate shock that matters. Our theory treats latent cultivation productivity as given, although productivity starts to rise after cultivation begins. By contrast, Ashraf and Michalopoulos focus on a long run process of technological innovation before cultivation begins. In principle these two approaches are complementary, although the relative importance of the differing causal channels is an empirical question.

The remainder of the paper is organized as follows. Section 2 describes global climate from the last Ice Age to the Holocene. Section 3 outlines the agricultural transition in southwest Asia. The model is developed in section 4 and used to explain events in southwest Asia in section 5. Section 6 surveys several other pristine cases in 
which the emergence of cultivation cannot be explained by diffusion from other societies where it already existed.

Section 7 looks at cases of non-transition. In our view, a key test for any theory of the agricultural transition is whether it can answer the following questions. Why were there relatively few pristine transitions? Why were there no transitions in previous interglacial periods? Why did agriculture not evolve during the last Ice Age? Why were there no cases in the initial warming phase of the current interglacial? Why is there no evidence of pristine transitions in tropical rainforests? Why did agriculture not arise independently in Japan and the northwest coast of North America, regions that had large sedentary populations, sophisticated technologies, and complex cultures? Why can't nontransitions be fully explained by poor endowments of domesticable plants and animals? We will argue that our framework provides coherent answers to these questions.

Section 8 summarizes our contributions to the literature on agricultural origins. These include providing an explanation for initial cultivation (with empirical support); demonstrating that biased climate change, a key assumption in other work, is unnecessary for this transition; identifying neglected factors that appear to be important, at least for southwest Asia and perhaps elsewhere (heterogeneous production sites and migration); and endogenizing two variables often treated as exogenous (population and technology).

\section{Global Climate History}

Climate reconstruction (paleoclimatology) involves observations on polar ice, alpine glaciers, ocean and lake sediments, tree rings, calcite precipitated on the walls of caves, growth bands in corals, and the chemistry of marine shells. Polar ice cores have more than 40 distinct climate-related properties and provide data on temperature, rainfall, 
ice volume, and atmospheric $\mathrm{CO}_{2}$ concentrations. Ice cores from Dome $\mathrm{C}$ in eastern Antarctica allow inference of climatic conditions going back 740,000 years (Wolff et al., 2004; McManus, 2004), and confirm observations from Vostok in east Antarctica (going back 400,000 years), Greenland (80,000 years), and Atlantic ocean sediments (800,000 years).

These climate histories reveal a series of glacial periods (Ice Ages) lasting 100,000 years on average, interrupted by interglacial periods lasting 10,000 years on average. The glacial periods are characterized by low concentrations of $\mathrm{CO}_{2}$, cold and dry conditions, high variability in weather, and low sea levels. Interglacial periods manifest opposite conditions. Relative to the current interglacial, the last Ice Age involved a $30 \%$ reduction in atmospheric $\mathrm{CO}_{2}$ concentrations, a decrease in global mean annual temperature of 5 to 10 degrees Centigrade, and a drop of 125 meters in sea level (Cronin, 1999).

The last glacial maximum (LGM) occurred around 21,000 BP (all BP dating in this paper is in calibrated radiocarbon years and should be interpreted as calendar years before $\mathrm{AD} 1950)$. By $19,000 \mathrm{BP}$ the great ice sheets had begun to melt, by $16,000 \mathrm{BP}$ the climate exhibited large variations in temperature and rainfall, and shortly after 15,000 BP there was a dramatic increase in temperature that brought the Ice Age to an end. From 13,000 to $11,600 \mathrm{BP}$ an abrupt climate reversal occurred in which conditions returned to those characterizing the LGM. This event, the Younger Dryas, is detected throughout the northern hemisphere (Cronin, 1999: 202-221), though the exact timing varies by region. The very cold and dry conditions of the Younger Dryas gave way to a second dramatic increase in temperature and rainfall. Except for significant declines in temperature 
around $8200 \mathrm{BP}$ and $5000 \mathrm{BP}$, which may be relevant for some cases discussed in section 6, the subsequent Holocene climate regime has been relatively stable.

\section{Agricultural Origins in Southwest Asia}

Ohalo II provides the earliest evidence for extensive gathering of wild plants in southwest Asia, dating from 23,000 BP. This site was submerged under the Sea of Galilee and discovered in 1989 after water levels dropped dramatically. The inhabitants of Ohalo II gathered a broad range of grains (Weiss et al., 2004). A significant portion of their diet consisted of small-grained grasses, far smaller than the wild cereals we associate with the origin of agriculture (which were utilized as well). At this time of extreme aridity, much of southwest Asia was thinly populated or unoccupied. People lived in small campsites in groups ranging from one to five families and pursued a nomadic lifestyle.

During a warm and wet period before the Younger Dryas, Natufian communities flourished in southwest Asia (for a summary and bibliography, see Bar-Yosef, 2002a, 2002b). Population grew substantially and people became sedentary. Food was plentiful, and the skeletal evidence shows few signs of trauma. There is little evidence of conflict between groups. Migration of people and settlement patterns closely followed changes in biomass, which in turn was largely determined by the amount and distribution of winter rains. This way of life lasted more than 1500 years.

For cereals, peas, lentils, bitter vetch, and chickpeas--the early domesticates in southwest Asia--a key difference from wild varieties is that domesticated crops cannot reseed themselves. Therefore if domesticated seeds are found, this indicates the existence of cultivation because the seeds in question must have been both planted and harvested, 
not just harvested. Details on the morphological markers of domestication are provided by Harlan (1995), Smith (1998), and Moore et al. (2000).

Artificial selection takes time so there is a lag between the point at which cultivation begins and the point at which it results in observable domestication. Previously this lag was estimated at no more than a few centuries (perhaps much less) for cereal crops in southwest Asia (Hillman and Davies, 1990). However, more recent archaeological research and field experiments have overturned this earlier view, and the current consensus is that the time lag was at least a millennium (Tanno and Wilcox, 2006; Balter, 2007). Thus, dates for the earliest findings of domesticated seeds are somewhat problematic proxies for dates of initial cultivation.

Early evidence of cultivation has been found at Abu Hureyra, a village on the Euphrates River located on the ecotone between the Euphrates Valley and the woodlandsteppe in what is today northwest Syria (data are from Moore et al., 2000; Hillman et al., 2001). This village was founded around 13,500 BP. Excavation has uncovered two superimposed settlements. Abu Hureyra 1 was inhabited by sedentary foragers. The remains of food plants at 13,500 BP reflect a diverse diet typical of hunter-gatherer societies. There is no evidence for the cultivation of crops here or at any Natufian site before the advent of the Younger Dryas, which for this region is dated from around $13,000 \mathrm{BP}$ to $11,600 \mathrm{BP}$ (for details of the timing of climate change in southwest Asia, see Wright and Thorpe, 2003).

The use of several wild foods, including some caloric staples, diminished rapidly in the early stages of the Younger Dryas, and the sequence in which individual species declined is consistent with advancing desiccation. The decline in wild cereals was 
immediately followed by a rapid rise in a weed flora typical of arid-zone cultivation involving substantial tillage. Additional evidence for cultivation at Abu Hureyra comes from the reappearance of lentils and other large-seeded legumes that had been locally absent for several centuries, even though the arid conditions associated with their initial disappearance still prevailed. According to Hillman et al. (2001), these events suggest that cultivation was precipitated by the decline in wild cereals and that environmental stress was the trigger.

A puzzle arises from the alleged discovery at Abu Hureyra of domesticated rye seeds dated to around a century after initial cultivation. This potential finding is inconsistent with the current view that it takes at least 1000 years after cultivation for domesticated seeds to appear. The puzzle has been resolved by rejecting the claim of domesticated rye seeds based on the ambiguity of the evidence at Abu Hureyra, a lack of corroborating evidence from elsewhere in the region, the possibility of intrusion from higher levels of the excavation, and doubts about the reliability of the radiocarbon dates (Nesbitt, 2002; Balter, 2007).

The population of Abu Hureyra grew to perhaps 100 - 300 people at its maximum during the Younger Dryas. Population in southwest Asia as a whole was contracting in this period and many sites were abandoned. While the Natufian population returned to a nomadic lifestyle across much of the region, often with unsuccessful results (Bar-Yosef and Meadow, 1995; Bar-Yosef, 2002a, 2002b), an alternative choice was to migrate to sites located in river valleys and on lake shores where water was close at hand, and where expanses of fertile soils became available as rivers and lakes shrank due to greater aridity (Bar-Yosef, 2002a: 116; Mithen, 2003: 53). The migration of population to Abu Hureyra 
is a well-documented example of this second option. The lack of evidence for violence or fortifications at Abu Hureyra suggests that this migration process was peaceful.

Access to reliable water supplies and fertile soils also characterized the other sites in southwest Asia that experienced an early transition to agriculture (Smith, 1998). Bellwood (2005: 57) describes the sites in southwest Asia with the oldest potentially domesticated cereal remains as follows: "[A]1l were located near springs, lakes, or riverine water sources. Such sites include Jericho, Netiv Hagdud, Gilgal, Tell Aswad, Abu Hureyra, and Mureybet. Early agricultural sites elsewhere, such as Ali Kosh in Khusistan, had similar advantages.”

After the end of the Younger Dryas at Abu Hureyra, population in the village declined, indicating an out-migration to previously arid locations. Abu Hureyra 2 is dated from roughly 11,400 BP. The villagers were farmers who also collected some wild plants and hunted game, but eventually became wholly dependent on their crops and domesticated animals. Population increased rapidly to levels more than twenty times the population of Abu Hureyra 1 and surpassed in size almost all other contemporary sites in southwest Asia.

Evidence of early cultivation has also been found at other sites in southwest Asia. Weiss et al. (2006) rely on two empirical markers for cultivation: the presence of larger seed quantities than could have been harvested from local stands of the wild plant, and the presence of seeds from certain weeds that grow as a by-product of cultivation. These weeds are always found together with cultivation in contemporary fields in the same geographic area, and are never found in the absence of cultivation. Mureybit is near Abu Hureyra on the Euphrates River and provides similar evidence of cultivation during the 
Younger Dryas in the form of field weeds (Colledge 1998, 2002). Other early cultivation sites date from the "Pre-Pottery Neolithic A" (PPNA) period, roughly 11,800 to 10,800 BP (see Weiss et al., 2006, for a detailed description).

While there is disputed evidence of domesticated seeds in the PPNA, the early "Pre-Pottery Neolithic B" (PPNB) period (roughly 10,800 to 10,400 BP) provides unambiguous evidence of plant domestication (Nesbitt, 2002). Using the time lag of 1000 or more years between cultivation and domestication, these findings provide additional evidence that cultivation first occurred during the Younger Dryas.

\section{The Formal Model}

We consider a large geographic region with a continuum of production sites. People and technological knowledge move freely within the region. At each site there are two sources of food, foraging and cultivation, which are perfect substitutes in consumption. We view foods as caloric staples for reasons explained in sections 6 and 7 . A parameterized version of the model is presented in Dow, Olewiler, and Reed (2005).

The production function for foraging is $\mathrm{F}\left(\mathrm{n}_{\mathrm{f}}, \mathrm{c}, \mathrm{s}\right)$ and the production function for cultivation is $G\left(n_{g}, c, s\right)$ where $n_{f} \geq 0$ is foraging labor, $n_{g} \geq 0$ is cultivation labor, $c \in[0,1]$ is climate, and $\mathrm{s} \in[0,1]$ is site quality. Climate refers to the average temperature and precipitation across the region as a whole. Site quality is a fixed characteristic of a location, perhaps reflecting access to fresh water or fertile soil. Because we will allow free mobility both for foragers and farmers (see the discussion of migration later in this section), the distinction between nomadism and sedentism plays no role in the analysis. 
A1 Both $F\left(n_{f}, c, s\right)$ and $G\left(n_{g}, c, s\right)$ are twice continuously differentiable. All inputs are essential. When the inputs are strictly positive, each function is increasing in its arguments and all second derivatives are strictly negative.

The adult population (n) at a given site allocates labor to obtain the total output

(1) $\mathrm{H}(\mathrm{n}, \mathrm{c}, \mathrm{s}) \equiv\left\{\max \mathrm{F}\left(\mathrm{n}_{\mathrm{f}}, \mathrm{c}, \mathrm{s}\right)+\mathrm{G}\left(\mathrm{n}_{\mathrm{g}}, \mathrm{c}, \mathrm{s}\right)\right.$ subject to $\mathrm{n}_{\mathrm{f}} \geq 0, \mathrm{n}_{\mathrm{g}} \geq 0$, and $\left.\mathrm{n}_{\mathrm{f}}+\mathrm{n}_{\mathrm{g}}=\mathrm{n}\right\}$

$\mathrm{H}$ is continuous in $(\mathrm{n}, \mathrm{c}, \mathrm{s})$ and strictly concave in $\mathrm{n}$ for any fixed $(\mathrm{c}, \mathrm{s})>0$. The optimal labor allocation and total output $\mathrm{H}$ are differentiable functions of $(\mathrm{n}, \mathrm{c}, \mathrm{s})$ except possibly at the boundary $n=n^{a}(c, s)$ defined in A2.

A2 Given $(\mathrm{c}, \mathrm{s})>0$, there is a population threshold $\mathrm{n}^{\mathrm{a}}(\mathrm{c}, \mathrm{s})>0$ such that for $\mathrm{n} \leq \mathrm{n}^{\mathrm{a}}(\mathrm{c}, \mathrm{s})$ it is optimal to set $n_{f}=n$ and $n_{g}=0$ (foraging dominates), while for $n>n^{a}(c, s)$ it is optimal to set $n_{\mathrm{f}}>0$ and $\mathrm{n}_{\mathrm{g}}>0$ (some labor is allocated to cultivation).

Assumptions of this type are standard in the literature (Weisdorf, 2005). The threshold $\mathrm{n}^{\mathrm{a}}(\mathrm{c}, \mathrm{s})$ is determined by equating marginal products:

$$
\mathrm{F}_{\mathrm{n}}\left[\mathrm{n}^{\mathrm{a}}(\mathrm{c}, \mathrm{s}), \mathrm{c}, \mathrm{s}\right] \equiv \mathrm{G}_{\mathrm{n}}(0, \mathrm{c}, \mathrm{s})
$$

Better climate or site quality need not favor foraging over cultivation or vice versa. We will say that climate and site quality are neutral if $\mathrm{n}^{\mathrm{a}}$ is a constant that does not depend on $(\mathrm{c}, \mathrm{s})$. This is true if the production functions have the multiplicative form

$$
\mathrm{F}\left(\mathrm{n}_{\mathrm{f}}, \mathrm{c}, \mathrm{s}\right)=\mathrm{A}(\mathrm{c}, \mathrm{s}) \mathrm{f}\left(\mathrm{n}_{\mathrm{f}}\right) \quad \text { and } \quad \mathrm{G}\left(\mathrm{n}_{\mathrm{g}}, \mathrm{c}, \mathrm{s}\right)=\mathrm{kA}(\mathrm{c}, \mathrm{s}) \mathrm{g}\left(\mathrm{n}_{\mathrm{g}}\right)
$$


where $\mathrm{k}>0$ is a productivity parameter. A3 implies that the population threshold $\mathrm{n}^{\mathrm{a}}$ is a decreasing function of the cultivation productivity $\mathrm{k}$, a fact that will become important in section 5. A3 also implies that total output has the form $H(n, c, s)=A(c, s) h(n)$ and the optimal labor allocation for a given $\mathrm{n}$ is independent of $(\mathrm{c}, \mathrm{s})$. A3 will be used throughout sections 4 and 5 in order to show that the agricultural transition can be explained without appealing to climate biases that directly favor cultivation. Biased climate effects will be discussed in section 8 .

Per capita food output at a site of quality $s$ is

$$
\mathrm{y}(\mathrm{n}, \mathrm{c}, \mathrm{s}) \equiv \mathrm{H}(\mathrm{n}, \mathrm{c}, \mathrm{s}) / \mathrm{n}
$$

Due to the strict concavity of $\mathrm{H}$, per capita output (y) is decreasing in local population (n). It is convenient to assume

$$
\lim _{n \rightarrow 0} y(n, c, s)=+\infty \text { and } \lim _{n \rightarrow \infty} y(n, c, s)=0 \text { for fixed }(c, s)>0 \text {. }
$$

The inverse of $y(n, c, s)$ is written $n(y, c, s)$ and gives local population density as a function of per capita food $(\mathrm{y})$ for any fixed climate and site quality $(\mathrm{c}, \mathrm{s})>0$.

A time period is taken to be a human generation (15-25 years). The only important feature of our population model is that the number of surviving children (r) for an adult is an increasing function of that adult's food income (y). Such a relationship could arise in many ways. In a Darwinian framework, one might treat $r(y)$ itself as the (indirect) utility function. More conventionally, $r$ could simply be one argument in the adult's (direct) utility function, as long as the number of surviving children is a normal good. In either case, 
The last part of A5 ensures that population grows when food income is high enough.

Let the number of adults at a typical site of quality $s$ at the start of period $t$ be $n_{s t}{ }^{\circ}$. All sites of the same quality enter the model symmetrically. In each period, events occur in the following sequence.

1. The climate $c_{\mathrm{t}}$ and site qualities $\mathrm{s}$ are observed by all adults.

2. Each adult decides whether to stay at her current site or move elsewhere. These decisions determine new population levels at each site, denoted by $\mathrm{n}_{\mathrm{st}}$.

3. The adults at each site obtain food by allocating labor to foraging and cultivation as in equation (1) above. Food is shared equally at the site, yielding $\mathrm{y}_{\mathrm{st}}$ per adult.

4. The current adults die at the end of period $t$. At the start of period $t+1$ the initial population at a typical site of quality $\mathrm{s}$ is $\mathrm{n}_{\mathrm{s}, \mathrm{t}+1}{ }^{\circ}=\mathrm{r}\left(\mathrm{y}_{\mathrm{st}}\right) \mathrm{n}_{\mathrm{st}}$ and the process repeats.

Because utility is increasing in y, adults prefer sites with more food per adult. We assume an open access property regime where insiders cannot exclude outsiders. If there are no mobility costs and each adult treats the post-migration population at each site $\left(\mathrm{n}_{\mathrm{st}}\right)$ as parametric, then food per adult $\left(\mathrm{y}_{\mathrm{st}}\right)$ must be equalized across sites in each period. Thus every site has the same rate of natural population growth or decline $r\left(\mathrm{y}_{\mathrm{st}}\right)$ in period $\mathrm{t}$.

The open access assumption is a convenient way to generate a positive short run relationship between site quality and population density, as we explain below, but a similar relationship can arise under more complex property rights systems that impede full utility equalization. For example, foragers can often move to better locations by 
exploiting kinship networks, creating a tendency for population to concentrate at good sites (Kelly, 1995). Our qualitative results survive as long as this tendency exists.

Short run equilibrium. Let $\mathrm{N}_{\mathrm{t}}$ be the total population mass for the region as a whole in period t. This fixed population is distributed across sites to equalize food per capita. The resulting output per person $y_{t}$ must satisfy the short run equilibrium condition

$$
\mathrm{N}_{\mathrm{t}}=\int_{0}{ }^{1} \mathrm{n}\left(\mathrm{y}_{\mathrm{t}}, \mathrm{c}_{\mathrm{t}}, \mathrm{s}\right) \mathrm{q}(\mathrm{s}) \mathrm{ds}
$$

where $n(y, c, s)$ is the inverse of $y(n, c, s)$ defined earlier and $q(s)$ is the density function for site quality (assumed to be positive everywhere). Using A4, equation (4) has a unique solution $\mathrm{y}_{\mathrm{t}}=\mathrm{Y}\left(\mathrm{N}_{\mathrm{t}}, \mathrm{c}_{t}\right)$ for any $\left(\mathrm{N}_{\mathrm{t}}, \mathrm{c}_{\mathrm{t}}\right)>0$ where $\mathrm{Y}$ is decreasing in $\mathrm{N}_{\mathrm{t}}$ and increasing in $\mathrm{c}_{\mathrm{t}}$. Writing $n_{s t}=n\left[Y\left(N_{t}, c_{t}\right), c_{t}, s\right]$ it is easy to show that the population density $n_{s t}$ is increasing in site quality s. Thus, a necessary and sufficient condition for cultivation is $n\left(y_{t}, c_{t}, 1\right)>$ $\mathrm{n}^{\mathrm{a}}$. If cultivation occurs at all, it must occur at the best sites $(\mathrm{s}=1)$.

We now impose further structure on the production technology.

A6 The function $\mathrm{A}(\mathrm{c}, \mathrm{s})$ from $\mathrm{A} 3$ has constant returns to scale and an elasticity of substitution greater than unity.

Proposition. If A6 holds and $\mathrm{N}$ is fixed, an increase in c decreases population density $\mathrm{n}[\mathrm{Y}(\mathrm{N}, \mathrm{c}), \mathrm{c}, 1]$ at the best sites.

The proof is provided in an appendix but the intuition is not difficult. Suppose climate improves from $\mathrm{c}_{0}$ to some higher value $\mathrm{c}_{1}$. If this increases $\mathrm{A}(\mathrm{c}, \mathrm{s})$ by the same proportion $\theta$ for all $\mathrm{s} \in[0,1]$, per capita output also rises by $\theta$ and the distribution of the total population $\mathrm{N}$ across sites does not change. But when the ratio $\mathrm{A}\left(\mathrm{c}_{1}, \mathrm{~s}\right) / \mathrm{A}\left(\mathrm{c}_{0}, \mathrm{~s}\right)$ is a 
decreasing function of site quality, it is necessary to redistribute the fixed total population from good sites to worse ones in order to maintain short run equilibrium. The condition A6 guarantees this outcome.

A better climate therefore flattens the distribution of regional population by lowering densities at sites with quality above some $\mathrm{s}_{0} \in(0,1)$ and raising densities at sites below $\mathrm{s}_{0}$. Conversely, a worse climate makes the distribution steeper by increasing population density at the top end and decreasing it at the bottom. This is the fundamental mechanism we will use to link climate change with cultivation in section 5.

Long run equilibrium. Because all sites have the same population growth rate, we can write $\mathrm{N}_{t+1}=r\left[\mathrm{Y}\left(\mathrm{N}_{t}, \mathrm{c}_{t}\right)\right] \mathrm{N}_{\mathrm{t}}$. From A5 there is a unique $\mathrm{y}^{*}>0$ with $\mathrm{r}\left(\mathrm{y}^{*}\right)=1$. From A4 we can define the long run equilibrium population $\mathrm{N}^{*}(\mathrm{c})$ for any climate $\mathrm{c}>0$ by

$$
\mathrm{N}^{*}(\mathrm{c}) \equiv \int_{0}^{1} \mathrm{n}\left(\mathrm{y}^{*}, \mathrm{c}, \mathrm{s}\right) \mathrm{q}(\mathrm{s}) \mathrm{ds}
$$

This is the aggregate population that yields per capita output $\mathrm{y}^{*}$ at all sites when climate is c. As long as $r[\mathrm{Y}(\mathrm{N}, \mathrm{c})] \mathrm{N}$ is increasing in $\mathrm{N}$ (that is, the direct positive effect of $\mathrm{N}$ exceeds the indirect negative effect operating through $\mathrm{Y}$ and $\mathrm{r}$ ), with constant climate the sequence $\left\{\mathrm{N}_{0}, \mathrm{~N}_{1} \ldots\right\}$ converges monotonically to $\mathrm{N}^{*}(\mathrm{c})$ from any initial population $\mathrm{N}_{0}$.

\section{The Effects of Climate Change}

This section applies the model to the case of southwest Asia discussed in section 3. We consider the climate sequence $\left\{\mathrm{c}_{\mathrm{IA}}, \mathrm{c}_{\mathrm{WA}}, \mathrm{c}_{\mathrm{RV}}, \mathrm{c}_{\mathrm{RC}}\right\}$ where $\mathrm{IA}=$ Ice Age, WA $=$ initial warming, $\mathrm{RV}=$ climate reversal, and $\mathrm{RC}=$ climate recovery. In view of the climate data from sections 2 and 3 , we assume $\mathrm{c}_{\mathrm{IA}}<\mathrm{c}_{\mathrm{RV}}<\mathrm{c}_{\mathrm{WA}}<\mathrm{c}_{\mathrm{RC}}$. 
Ice Age. Denote long run regional population at the LGM by $\mathrm{N}_{\mathrm{IA}}=\mathrm{N}^{*}\left(\mathrm{c}_{\mathrm{IA}}\right)$. The absence of cultivation in the last Ice Age indicates that even at the best sites $(\mathrm{s}=1)$, local population density $\mathrm{n}\left(\mathrm{y}^{*}, \mathrm{c}_{\mathrm{IA}}, 1\right)$ was below the agricultural threshold $\mathrm{n}^{\mathrm{a}}$. We take this long run equilibrium as a starting point.

Initial Warming. In the short run, a climate improvement to $c_{\mathrm{wA}}$ would increase per capita food throughout the region according to the function $y=Y\left(N_{I A}, c\right)$ with population temporarily fixed at $\mathrm{N}_{\mathrm{IA}}$ (a move from A to B in Figure 1). Using condition A6, the proposition from section 4 shows that cultivation cannot be a short run response to this improvement, because population density falls at the best sites:

$$
\mathrm{n}\left[\mathrm{Y}\left(\mathrm{N}_{\mathrm{IA}}, \mathrm{c}_{\mathrm{WA}}\right), \mathrm{c}_{\mathrm{WA}}, 1\right]<\mathrm{n}\left[\mathrm{Y}\left(\mathrm{N}_{\mathrm{IA}}, \mathrm{c}_{\mathrm{IA}}\right), \mathrm{c}_{\mathrm{IA}}, 1\right] \equiv \mathrm{n}\left(\mathrm{y}^{*}, \mathrm{c}_{\mathrm{IA}}, 1\right)<\mathrm{n}^{\mathrm{a}} .
$$

If cultivation is not in use at the best sites, it cannot be used at inferior sites either. The short run reduction in population for $\mathrm{s}=1$ is shown as a move from A to B in Figure 2.

This result requires that the elasticity of substitution in $\mathrm{A}(\mathrm{c}, \mathrm{s})$ between climate $(\mathrm{c})$ and site quality (s) exceed unity, which we believe is a natural assumption. The critical role of climate improvement in southwest Asia was to enhance plant growth through increased precipitation. More precipitation would not have provided a large marginal gain at high-quality sites endowed with permanent water sources (rivers, lakeshores, marshes, or springs), but it would have been significant at less attractive locations. In brief, water from the sky was a close substitute for water from the ground. The short run implication of greater rainfall would thus have been to redistribute regional population away from the best sites toward others where the gain was proportionately larger. This is 
consistent with the observed migration of people into previously arid landscapes as the Ice Age abated.

Assuming the new climate $c_{\mathrm{wA}}$ remained in effect, in the long run population would have risen to a higher steady state $\mathrm{N}_{\mathrm{WA}}=\mathrm{N}^{*}\left(\mathrm{c}_{\mathrm{WA}}\right)$ and food per capita would eventually have returned to $\mathrm{y}^{*}$ (a move from $\mathrm{B}$ to $\mathrm{C}$ in Figure 1). In reality, climate did not improve in a one-time jump, but this is not an essential part of our story. The important point is that even after climate reached its best level during the lengthy Natufian period, the increased long run population density at the best sites $\mathrm{n}\left(\mathrm{y}^{*}, \mathrm{c}_{\mathrm{wA}}, 1\right)$ was still not enough to stimulate cultivation (see the move from B to C in Figure 2).

Climate Reversal. Now consider an abrupt deterioration in climate from $\mathrm{c}_{\mathrm{WA}}$ to $\mathrm{c}_{\mathrm{RV}}$ (in southwest Asia, the Younger Dryas), where in the short run regional population stays fixed at the level $\mathrm{N}_{\mathrm{WA}}$ inherited from the initial warming.

The short run effect runs in the opposite direction to that of the initial warming: food per capita diminishes (a move from C to D in Figure 1) while regional population remains temporarily constant at $\mathrm{N}_{\mathrm{WA}}$. More significantly, population rises at the best sites (the move from $\mathrm{C}$ to $\mathrm{D}$ in Figure 2). At Abu Hureyra, this led relatively quickly to cultivation. Algebraically, we have

$$
\mathrm{n}\left(\mathrm{y}^{*}, \mathrm{c}_{\mathrm{wA}}, 1\right) \equiv \mathrm{n}\left[\mathrm{Y}\left(\mathrm{N}_{\mathrm{WA}}, \mathrm{c}_{\mathrm{WA}}\right), \mathrm{c}_{\mathrm{wA}}, 1\right]<\mathrm{n}^{\mathrm{a}}<\mathrm{n}\left[\mathrm{Y}\left(\mathrm{N}_{\mathrm{WA}}, \mathrm{c}_{\mathrm{RV}}\right), \mathrm{c}_{\mathrm{RV}}, 1\right]
$$

The reasoning involves another application of the proposition in section 4 . As precipitation declined, refugees fled sites that lacked permanent water sources and sought sanctuary at better locations. This is consistent with the fact that many sites were abandoned during the Younger Dryas, and also with the fact that the sites in continued 
use (such as Abu Hureyra) were the ones that depended less on rainfall. As noted in section 3, the population of Abu Hureyra grew in this phase, probably due to inmigration, while total regional population declined. Bar-Yosef (2002a: 116) likewise suggests that as marginal areas became drier, kinship-based relocation caused population to rise in the fertile belt of the Levant.

Whether a climate reversal triggers cultivation in the short run depends on the size of the regional population when the negative shock hits. For any given climate, let $\mathrm{y}^{\mathrm{a}}(\mathrm{c})$ $\equiv \mathrm{y}\left(\mathrm{n}^{\mathrm{a}}, \mathrm{c}, 1\right)$ be food per capita when population at the best sites is exactly at the threshold for cultivation. When $\mathrm{y}<\mathrm{y}^{\mathrm{a}}(\mathrm{c})$, it follows that $\mathrm{n}(\mathrm{y}, \mathrm{c}, 1)>\mathrm{n}^{\mathrm{a}}$ so cultivation occurs at the best sites. Substituting $\mathrm{y}^{\mathrm{a}}\left(\mathrm{c}_{\mathrm{RV}}\right)$ into (4) gives the regional population threshold $\mathrm{N}^{\mathrm{a}}\left(\mathrm{c}_{\mathrm{RV}}\right)$ beyond which cultivation occurs. Using (5) to compute the long run population $\mathrm{N}^{*}\left(\mathrm{c}_{\mathrm{WA}}\right)$ inherited from the initial warming phase, cultivation begins if and only if

$$
\mathrm{N}^{*}\left(\mathrm{c}_{\mathrm{WA}}\right) \equiv \int_{0}^{1} \mathrm{n}\left(\mathrm{y}^{*}, \mathrm{c}_{\mathrm{WA}}, \mathrm{s}\right) \mathrm{q}(\mathrm{s}) \mathrm{ds}>\int_{0}^{1} \mathrm{n}\left[\mathrm{y}^{\mathrm{a}}\left(\mathrm{c}_{\mathrm{RV}}\right), \mathrm{c}_{\mathrm{RV}}, \mathrm{s}\right] \mathrm{q}(\mathrm{s}) \mathrm{ds} \equiv \mathrm{N}^{\mathrm{a}}\left(\mathrm{c}_{\mathrm{RV}}\right)
$$

Because inequality (8) gives a necessary and sufficient condition for the initial transition to cultivation, we pause to provide some interpretative details.

First, a larger pre-existing regional population makes a transition more likely, ceteris paribus. This follows immediately from the appearance of $\mathrm{N}^{*}\left(\mathrm{c}_{\mathrm{WA}}\right)$ on the lefthand side. Second, a more severe climate reversal is more likely to trigger a transition, ceteris paribus. This follows from the fact that the right-hand side is increasing in $c_{R V}$ (the proof involves A3 and A6, and parallels the proof of the proposition in section 4).

A transition also becomes more likely when the latent productivity of cultivation is higher, ceteris paribus. Recall that the local population threshold $\mathrm{n}^{\mathrm{a}}$ is a decreasing 
function of the cultivation productivity parameter $\mathrm{k}$ introduced in A3. This implies that $\mathrm{y}^{\mathrm{a}}\left(\mathrm{c}_{\mathrm{RV}}\right)$ is increasing and $\mathrm{N}^{\mathrm{a}}\left(\mathrm{c}_{\mathrm{RV}}\right)$ is decreasing in this parameter, making (8) more likely to hold when cultivation productivity is high. If technological progress tends to raise the latent productivity of cultivation relative to the actual productivity of foraging over time (Ashraf and Michalopoulos, 2006), it becomes easier to satisfy (8). Conversely, if latent cultivation productivity had been very low, even a massive shock like the Younger Dryas would not have been enough to trigger a transition.

Finally, a transition is more likely when a region has few good sites but many bad ones, ceteris paribus. To see why, hold pre-existing population $\mathrm{N}^{*}\left(\mathrm{c}_{\mathrm{WA}}\right)$ fixed on the lefthand side of (8) and consider the site density function $\mathrm{q}(\cdot)$ on the right-hand side. The function $\mathrm{n}\left[\mathrm{y}^{\mathrm{a}}\left(\mathrm{c}_{\mathrm{RV}}\right), \mathrm{c}_{\mathrm{RV}}, \mathrm{s}\right]$ does not depend on $\mathrm{q}(\cdot)$ and it is increasing in $\mathrm{s}$. Thus a shift toward a less favorable site distribution in the sense of first-order dominance will lower the right-hand side and make it easier to satisfy inequality (8).

As the Younger Dryas took hold, reduced food per capita led to a loss of regional population and this alleviated the pressure on the best sites. If the climate reversal had been permanent and technology had been constant, eventually population would have declined to $\mathrm{N}_{\mathrm{RV}}=\mathrm{N}^{*}\left(\mathrm{c}_{\mathrm{RV}}\right)$ and food per capita would have returned to $\mathrm{y}^{*}$ (the dashed curve from $\mathrm{D}$ to $\mathrm{E}$ in Figure 1). Since long run population density in the initial warming was insufficient to support cultivation, the still lower long run population of the Younger Dryas would also have failed to do so. In this scenario, cultivation would have been only a stopgap on the way back to universal foraging (see the dashed curve in Figure 2).

In reality, however, the practice of cultivation in southwest Asia led to increases in productivity through better knowledge about important technological details: optimal 
times for planting and harvesting, optimal locations, correct spacing and depth of seeds, the best methods of weeding and irrigation, etc. Eventually artificial selection on the genetic characteristics of plants culminated in full domestication. In our model, this productivity growth shows up as an increase in the parameter k defined in A3.

We assume that productivity gains were freely available to everyone in the region. Productivity improvement can be modeled in many ways and only broad qualitative issues are pertinent here. Suppose that before cultivation begins, its latent productivity is $\mathrm{k}_{0}$. Let the region-wide population mass engaged in cultivation be

$$
\mathrm{M} \equiv \int_{\mathrm{S}}{ }^{1} \mathrm{n}_{\mathrm{g}}[\mathrm{Y}(\mathrm{N}, \mathrm{c}, \mathrm{k}), \mathrm{c}, \mathrm{k}, \mathrm{s}] \mathrm{q}(\mathrm{s}) \mathrm{ds}
$$

where $S=S(N, c, k)$ is the marginal site quality for cultivation and $n_{g}$ is the optimal input of labor to cultivation given the local population density $n[Y(N, c, k), c, k, s]$. A simple and general model for productivity growth is

$$
\mathrm{k}_{\mathrm{t}+1}=\phi\left(\mathrm{k}_{\mathrm{t}}, \mathrm{M}_{\mathrm{t}}\right)
$$

where $\phi$ is increasing in $\mathrm{M}_{\mathrm{t}}$ and $\mathrm{k}_{\mathrm{t}+1}=\mathrm{k}_{\mathrm{t}}$ when $\mathrm{M}_{\mathrm{t}}=0$. Thus when cultivation is active, its productivity rises at a rate that depends on the total labor input to this activity. When cultivation is inactive, its productivity remains constant. We derive these features of the innovation process from first principles in Dow and Reed (2008).

Whether cultivation persists during a climate reversal depends on the outcome of a race between population and technology. As regional population falls, the local densities at individual sites also fall, which reduces the number of sites using cultivation as well as the amount of labor allocated to it at any given site. This slows technical 
progress and could ultimately shut down cultivation completely. On the other hand, as productivity improves, more sites adopt cultivation and additional labor is allocated to it where it is already in use. These effects promote further technical progress and slow down the rate of population loss by cushioning the blow to living standards.

The resulting dynamics are shown in Figure 3 (climate is held constant at $c_{\mathrm{RV}}$ ). The curve $\mathrm{N}^{\mathrm{a}}(\mathrm{k})$ shows the maximum regional population consistent with universal foraging at each possible productivity level $(\mathrm{k})$ for cultivation. This is obtained by first computing the cultivation threshold $\mathrm{n}^{\mathrm{a}}(\mathrm{k})$ as a function of $\mathrm{k}$, then finding the per capita food $y^{a}(k)$ when local population is exactly $n^{a}(k)$ at the best sites, and finally finding the regional population $\mathrm{N}^{\mathrm{a}}(\mathrm{k})$ that is consistent with $\mathrm{y}^{\mathrm{a}}(\mathrm{k})$. The result is

$$
\mathrm{N}^{\mathrm{a}}(\mathrm{k}) \equiv \int_{0}^{1} \mathrm{n}\left[\mathrm{y}^{\mathrm{a}}(\mathrm{k}), \mathrm{c}_{\mathrm{RV}}, \mathrm{s}\right] \mathrm{q}(\mathrm{s}) \mathrm{ds}
$$

We omit $\mathrm{k}$ as a separate argument of $\mathrm{n}(\mathrm{y}, \mathrm{c}, \mathrm{s})$ because only foraging is relevant in (11). To the left of this curve, labor is allocated entirely to foraging at all sites and the latent productivity of cultivation remains constant. To the right, labor is allocated to cultivation at some sites and its productivity therefore rises over time.

The second curve $\mathrm{N}^{*}(\mathrm{k})$ shows the long run regional population corresponding to a given cultivation productivity $\mathrm{k}$. This is derived by finding local population densities for each site that are consistent with the food per capita $\mathrm{y}^{*}$, given the productivity $\mathrm{k}$, and then substituting these densities into (5):

$$
\mathrm{N}^{*}(\mathrm{k}) \equiv \int_{0}^{1} \mathrm{n}\left(\mathrm{y}^{*}, \mathrm{c}_{\mathrm{RV}}, \mathrm{k}, \mathrm{s}\right) \mathrm{q}(\mathrm{s}) \mathrm{ds}
$$


Below the $\mathrm{N}^{\mathrm{a}}(\mathrm{k})$ curve, $\mathrm{N}^{*}(\mathrm{k})$ is a vertical line at $\mathrm{N}_{\mathrm{RV}}$ because $\mathrm{k}$ is irrelevant when all labor is used for foraging. Above $\mathrm{N}^{\mathrm{a}}(\mathrm{k})$, cultivation occurs and $\mathrm{N}^{*}(\mathrm{k})$ is increasing in $\mathrm{k}$.

The starting point $\mathrm{P}$ involves the long run population $\mathrm{N}_{\mathrm{WA}}$ inherited from the initial warming phase and the latent cultivation productivity $\mathrm{k}_{0}$. As explained above, during the Younger Dryas this combination was sufficient to induce cultivation at good sites, so $\mathrm{P}$ is above the locus $\mathrm{N}^{\mathrm{a}}(\mathrm{k})$. Depending on the rate of productivity growth, two possibilities can occur. When learning by doing is slow, the system trajectory will hit the $\mathrm{N}^{\mathrm{a}}(\mathrm{k})$ curve below $\mathrm{Q}$, at a point like $\mathrm{R}$. Cultivation then shuts down and the system moves horizontally to the left, asymptotically approaching a point like S with the population $\mathrm{N}_{\mathrm{RV}}$.

If learning by doing is fast enough, however, the trajectory eventually rises above the productivity level $\mathrm{k}_{\mathrm{Q}}$. In this case it is impossible to return to pure foraging because $\mathrm{N}^{\mathrm{a}}(\mathrm{k})$ is to the left of $\mathrm{N}^{*}(\mathrm{k})$. Cultivation therefore becomes permanent and its productivity continues to rise. This process is limited only by the possibility of a ceiling on the productivity of cultivation at which technological opportunities are exhausted.

The archaeological evidence reveals that this latter trajectory was the one followed in southwest Asia during the Younger Dryas. In Figures 1 and 2, we assume that $\mathrm{k}$ has an upper bound $\mathrm{k}_{\max }$ and thus $\mathrm{n}^{\mathrm{a}}$ has a lower bound $\mathrm{n}_{\text {min }}^{\mathrm{a}}$. Improved cultivation technology implies a higher steady state population in Figure 1 (point $\mathrm{E}^{\prime}$ rather than E, with $\mathrm{N}_{\mathrm{RV}}{ }^{\prime}$ rather than $\mathrm{N}_{\mathrm{RV}}$ ). In Figure 2, population density at the best sites remains above the threshold $\mathrm{n}^{\mathrm{a}}(\mathrm{k})$, which declines to $\mathrm{n}_{\text {min }}^{\mathrm{a}}$ as $\mathrm{k}$ increases to $\mathrm{k}_{\max }$, resulting in a move from D to $E^{\prime}$. 
Climate Recovery. Finally, suppose the climate recovers. The short run effect on per capita food is given by the upward jump from $\mathrm{E}^{\prime}$ to $\mathrm{F}$ in Figure 1. As in the case of initial warming, there is a drop in local densities at the best sites due to out-migration (the downward jump from $E^{\prime}$ to $F$ in Figure 2). This need not shut down cultivation because technology has improved, reducing the threshold density $\mathrm{n}^{\mathrm{a}}$. The long run result is a larger regional population $\mathrm{N}_{\mathrm{RC}}$ than under any previous regime (from $\mathrm{F}$ to $\mathrm{G}$ in Figure 1) and higher densities at the best sites (the path beginning at point $\mathrm{F}$ in Figure 2). This scenario is consistent with evidence for Abu Hureyra, where we observe a relatively brief period of population decline at the end of the Younger Dryas, followed by renewed population growth as agriculture became increasingly dominant.

\section{6. $\quad$ Other Transitions}

Several authors have explored the incidence of agriculture empirically using cross-sectional anthropological data (Pryor, 1986, 2004; Keeley, 1995; Locay, 1997; Baker, 2007). One difficulty with these studies is that recent or contemporary foraging societies are found in rain forests, deserts, or the Arctic, and there is no reason to believe that early agriculture evolved in such environments. Another difficulty is that in our framework, cultivation is a short run response to a climate shock and only persists over time if relative rates of change in population and technology satisfy certain requirements. Cross-sectional studies, by contrast, generally assume that societies are at or near long run equilibrium for their natural environments. Because this approach does not speak to the issues we raise, we rely instead upon data-based historical narrative. 
The main task of this section is to review evidence about pristine transitions other than the one in southwest Asia. The data are inconclusive, but we are not aware of any cases that directly contradict our theory and most cases seem at least mildly supportive. We limit attention to evidence that is widely accepted in the archaeological community.

As will become clear, what is missing for our purposes is the ability to correlate the dating of climatic change with the dating of initial cultivation. For millet, rice, maize and the other founder crops outside of southwest Asia, we only have dates for early domestication. Absent independent data on cultivation, or the time lag between the start of cultivation and full domestication, the best we can do is to compare climate conditions with dates corresponding to the end of the transition to agriculture, not the beginning.

Africa. Around 14,000 BP there were freshwater lakes, ponds, and swamps in the central Sahara, but rainfall declined starting about 10,000 BP. This period was associated with greater use of wild grasses and proto-domestication of sheep. Shortly after 9000 BP, cattle were likely domesticated in the eastern Sahara independently of events in southwest Asia (Mithen, 2003: 492-8). Ice core data from the summit of Mt. Kilimanjaro have revealed that between 10,000-5000 BP East Africa was wetter and warmer than today. A decades-long drought occurred around $8300 \mathrm{BP}$ and another occurred between 5000 and 4000 BP (National Research Council, 2002: 34; Mithen, 2003: 453-4). These dates roughly coincide with two dips in global temperature (see section 2).

Plant domestication in Africa occurred in a broad band along the southern margin of the Sahara Desert, with no archaeological evidence of domestic crops prior to $4000 \mathrm{BP}$ (Bellwood, 2005: 99). According to Smith (1998: 110), various researchers believe "the timing of initial domestication of millet and sorghum was tied to the southward 
expansion of the desert, which intensified about 4000 years ago, displacing people south". Smith goes on to say (p. 112) that African rice may also fit this model. Bellwood (2005: 103) describes a similar archaeological consensus. Finally, Smith observes that settlements in the savanna zone from 5000-3000 BP were located on the shores of lakes, that fish were an important food source, and that wild rice, millet, and sorghum were probably harvested at such sites. This suggests a 'refuge' role for these locales.

China. It is generally accepted that there were two largely independent centers of pristine agriculture in China, one in the north in the Huanghe River valley and a second in the south in the Yangzi River valley (all data on China are from Lu, 1999, except where stated). Some archaeologists argue, however, that these were related aspects of a single overarching transition process (Bellwood, 2005).

In the plain north of the Huanghe, evidence for domesticated millet comes from the Cishan assemblage, dated to 8000-7700 BP. South of the Huanghe, the Peiligang culture gives evidence of millet cultivation during 8500-7500 BP. However, data for this region are incomplete and genuinely transitional sites have not yet been identified. Smith (1998: 133-140) stresses the favorable ecological features of the early farming villages, while Higham (1995: 134) argues that the Peiligang settlements were first occupied during a colder climate phase also experienced in the Yangzi valley. These known dates for north China approximately coincide with those for the global cooling event around 8200 BP (see section 2), although domestication could have occurred much earlier.

The key crop in the south was rice, for which there is evidence of domestication in the middle Yangzi valley dating to $9000-8000 \mathrm{BP}$. This is associated with the Pengtoushan culture. The nearby site of Bashidang provides good evidence of 
domesticated rice by $8000 \mathrm{BP}$. Both were located on alluvial plains, and Bashidang likely reflects an "initial stage of domestication" (Lu, 1999: 93). Higham suggests that settlement began at Pengtoushan during "a period that experienced a reduction in temperature following 1,500 years of progressive warming" (1995: 133) and argues that climate decline encouraged the domestication of rice and millet (1995: 147). After the climate recovered, rice cultivation spread widely in the south (1995: 153-4).

Recent research suggests a tantalizing connection with the Younger Dryas. Around 13,000 BP wild rice phytoliths are found in caves slightly south of the Yangzi River, but this evidence disappears during the cold and dry conditions of the Younger Dryas itself. At the close of this period, rice phytoliths returned, "claimed to be partly from a domesticated population" (Bellwood, 2005: 116). Whether clearer linkages can be established between the Younger Dryas and rice domestication remains to be seen.

New Guinea. Highland New Guinea was an independent center for domestication of bananas and taro, and perhaps also yams and sugar cane (Bellwood, 2005: 142-145). The dates are uncertain. However, it is interesting that such crops could also have been domesticated in lowland rainforest areas but were not. Bellwood suggests that domestication occurred in the highland valleys because this was the edge of the wild range for these plants, so foragers there were more exposed to environmental stresses than foragers in the tropical lowlands.

Mesoamerica. The domestication of maize from its wild ancestor teosinte ranks as one of the most important agricultural transitions. Dating has proceeded on two fronts. Matsuoka et al. (2002) infer from genetic data that maize was domesticated about 9000 years ago. Piperno et al. (2007) report preliminary evidence from archaeological sites in 
the Iguala valley of domesticated maize by 8500 years ago. This valley lies 720 meters above sea level. Climate data show that rainfall is highly seasonal and the area has a 7 to 8 month dry season-conditions that make it vulnerable to climate shocks.

This evidence and evidence of human migration into Mesoamerica around 15,000 years ago (Goebel et al., 2008) suggests that the combination of variable climate (including a modified version of the Younger Dryas) and the concentration of population in high altitude river valleys could have triggered initial cultivation of teosinte in Mexico. The large gap between the Younger Dryas and the known dates for full domestication is consistent with the likelihood of an especially protracted lag between cultivation and domestication in the case of maize. A similar argument may apply to squash, for which evidence of domestication dates back to 10,000 BP at Guila Naquitz (Flannery, 1986; Marcus and Flannery, 1996; Smith, 2001).

The Andes. Dillehay et al. (2007) report evidence of horticultural economies in a dry forest valley in the Andes dated from around 10,000 BP, although their claim of finding domesticated squash, peanuts, and other plants has been questioned (Balter, 2007: 1833). Well-accepted data on sedentary settlements, pottery, and agriculture date from around $5000 \mathrm{BP}$. The domesticated crops included squash, achira, and beans, but not maize (Bellwood, 2005: 159-164).

As in Mesoamerica, the combination of variable climate and a concentration of population in high altitude valleys may be related to the earliest evidence of horticulture in the Andes. Another periodic climate event appears to have begun around the time that agriculture became well established. El Niño-Southern Oscillation (ENSO) refers to oscillations in the Pacific Ocean between a warm tropical water phase and a cold-water 
phase. The gradual onset of this cycle and a general increase in climate variability began around 5800 BP (Sandweiss et al., 1999). Archaeological evidence shows that in this period, major debris slides wiped out coastal foraging villages and local fish populations disappeared due to migration to cooler water. The causal connection with plant cultivation in the Andean highlands is uncertain (Bellwood, 2005: 149), but some of the coastal population may have migrated to higher elevations, raising population densities there and triggering cultivation.

USA. There is strong evidence that several food plants (goosefoot, sunflower, and sumpweed) were domesticated in the Mississippi valley by $4000 \mathrm{BP}$, although "agriculture shows few signs of being very significant anywhere" before about $2500 \mathrm{BP}$ (Bellwood, 2005: 175). We do not pursue this case further because details are scarce. The cultivation of indigenous plants was eventually overtaken by the diffusion of maize from Mexico.

It should be clear from this review that there is no smoking gun among the pristine transitions outside southwest Asia. However, some cases seem promising for our theory (Africa, China), and others are potentially supportive (New Guinea, Mesoamerica, the Andes). Further research by archaeologists, geneticists, and climatologists is needed to render a final verdict in each case.

\section{7. $\quad$ Non-Transitions}

A general theory of agricultural origins should not only be consistent with known transitions, it should also be consistent with cases where no transition occurred. Ideally, it should address all of the questions we posed in the introduction. Our framework, unlike the available alternatives, provides consistent answers to these questions. 
Why a small number of pristine cases? Consider the conditions that must hold in order for our model to predict agriculture as a long run equilibrium. A period of 'good' climate must last long enough for regional population to accumulate sufficiently; the diet of the population must be sufficiently dependent on wild plants that are vulnerable to a climate shift; a negative climate shock must arrive suddenly enough that gradual population decline through fertility decisions does not solve the problem; a few sites must remain habitable while others are abandoned when the climate turns 'bad'; migration within the region must be sufficiently free; and the productivity of cultivation must rise quickly enough once it begins. The last requirement is only likely to be met if nature provides an endowment of wild plants that are relatively easy to domesticate. Multiplying the associated probabilities together yields a low probability of agriculture, which is consistent with the small number of pristine cases in the archaeological record.

Why no agriculture in earlier interglacials, during the last Ice Age, or in the initial warming after the last glacial maximum? The last interglacial comparable to our own occurred between 126,000 - 116,000 BP, with glacial conditions gradually intensifying during 116,000 - 78,000 BP. Anatomically modern humans did not live outside Africa in significant numbers until 70,000 - 50,000 BP (Campbell et al., 2006) and tropical Africa may have been buffered from large climate shocks, generating little incentive for cultivation there. In any case, cognitively modern humans may not have evolved until about 40,000 BP.

Another puzzle is why humans did not develop agriculture between about 40,000 BP and 13,000 BP, when there is little doubt that modern cognitive abilities existed. Richerson et al. (2001) attribute this to the low mean and high variance of weather during 
the last Ice Age, which deterred investments in agriculture. Our theory suggests a different view: climate instability ruled out long mild periods during which large regional populations could accumulate. There was no counterpart in the Ice Age to the 1500 years or more of mild, stable climate during which Natufian society arose in southwest Asia. Without this large pre-existing population, a climate reversal would not have caused a sufficient spike in population densities at the best sites and the cultivation threshold would never have been crossed. The climate reversal was evidently also necessary: the Natufians failed to embrace cultivation despite 1500 years of favorable conditions prior to the Younger Dryas.

Why no pristine agriculture in tropical rainforests? Bellwood (2005) observes that pristine agriculture never emerged in the rain forests of Africa (or for that matter, anywhere south of the equator in Africa), or in southeast Asia. Evidence for manioc cultivation in the Amazon is "nebulous" (2005: 151). Pristine agriculture also failed to arise in the lowlands of New Guinea or in tropical Australia. From our perspective, the obvious reason is that tropical regions were buffered from climate shifts, especially with regard to aridity (Higham, 1995, advances this argument for southeast Asia). Our key climate variable is rainfall, and by definition tropical rainforests seldom experience shortages of this resource. To the extent that high population densities did accumulate in the tropics, they were never threatened by events like the Younger Dryas, which was a phenomenon of the northern temperate zone.

Why no pristine agriculture in Japan or on the northwest coast of North America? These two cases drive home the point that a rich natural setting, a sedentary lifestyle, an innovative and industrious society, a complex culture, and a high population density are 
insufficient to bring about an agricultural economy. Moreover, both had severe Younger Dryas events and experienced the cooling of $8200 \mathrm{BP}$, making them especially relevant.

The Jomon period in Japan is dated from about 16,000 BP (information is from Habu, 2004). It is characterized by advanced technology (pottery) from a very early date, sedentism, and general prosperity, but a late transition (around $2500 \mathrm{BP}$ ) to full-scale rice farming. When cultivation finally arrived it appears to have been borrowed, along with other cultural characteristics, from the Mumun culture of the Korean peninsula. It is unclear whether this involved major population flows from Korea itself. A particularly striking fact is that rice cultivation could easily have been borrowed from China or Korea at much earlier dates, but it was not (Bellwood, 2005: 114).

The coastal inhabitants of the Pacific Northwest in North America are often used as the textbook example of a complex society not based on agriculture (see Johnson and Earle, 2000: 204-217). Fish were a key food source, especially the rich seasonal runs of salmon and eulachon. Many other wild foods were used, such as shellfish, waterfowl, marine and land mammals, roots, and berries, but by $8000 \mathrm{BP}$ salmon was the dominant food. Despite a promising environment with mild temperatures and ample precipitation, agriculture never became a core component of the economy (Deur, 1999, 2002).

Our explanation for the non-transition to agriculture in both of these societies is that they were cushioned from negative climate shocks by the availability of fresh water and marine dietary resources. This averted a shift to cultivation despite high population densities (according to Habu, 2004, this is a standard archaeological explanation for the failure of the Jomon to adopt agriculture). Moreover, site qualities may have been less heterogeneous that in southwest Asia (or Africa, or China), so climate shocks would have 
affected most sites in a parallel manner. This would have restrained migratory responses to such shocks, dampening the local population spikes needed to trigger cultivation.

These two cases highlight the fact that our model requires more than just a large climate reversal. If the reversal does not have a major impact on staple foods, it will not stimulate a transition. In addition we require a large regional population, high latent cultivation productivity, heterogeneous site quality, and induced migration to favorable locations. The Jomon and northwest coast examples exhibit climate reversals, large populations, and arguably high latent productivity. These conditions are necessary but by themselves were not sufficient.

Aren't non-transitions fully explained by poor endowments of domesticable plants and animals? Diamond (1997) argues that agriculture began in areas with especially favorable endowments of domesticable plants and animals. He suggests that seemingly promising regions such as California, southwestern and southeastern Australia, southern Africa, and Chile and Argentina were disqualified by their poor biological endowments. This 'supply side' idea is represented in our model by the latent productivity of cultivation prior to the transition, as well as the rate of productivity growth after cultivation begins (see section 5). However, it must be combined with 'demand side' factors (e.g. climate shocks) that drive foragers to adopt cultivation rather than simply harvesting their abundant wild resources. These demand factors are crucial in generating predictions about the location and timing of pristine transitions.

To see why biological endowments alone cannot provide a full explanation, consider the failure of the wild-rice-eating people of tropical southeastern Asia to initiate agriculture, in contrast to the people of southern China who did. These two populations 
had similar biological endowments, but a pristine transition only occurred in the region that was more exposed to climate shocks. Another example is the contrast between lowland (tropical) New Guinea with no transition, and highland (non-tropical) New Guinea where domestication of taro, bananas, and yams occurred. This difference can be traced to greater vulnerability to climate shocks in the highlands. The lack of cultivation in Japan and in northwest North America can be attributed more convincingly to good foraging opportunities that were relatively insensitive to climate shocks - that is, the lack of any demand for cultivation - than to a poor endowment on the supply side.

We close this section by emphasizing that our theory is open to refutation. If future research shows that agriculture evolved at some pristine location that was not vulnerable to climate shocks or where the initial cultivation of dietary staples did not coincide closely with a climate reversal, our theory would not apply and other explanations would have to be sought. A similar verdict would follow if pristine agriculture occurred in a region of low initial population density, if it occurred first at the lower-quality sites within a region, or if it was not accompanied by migration from poor sites to better ones.

\section{Conclusion}

We have developed a formal model and provided empirical support for a climatebased explanation of the origin of agriculture, arguably the most momentous event in human history. The paper also contributes to the existing literature in three other ways: by showing that biased climate change is not necessary in explaining the transition; by showing that some previously neglected factors are important (heterogeneous local sites, 
migration); and by endogenizing the roles of population and technology. We briefly address each point in turn.

Biased climate change. Much of the literature assumes either that a better climate made agriculture more attractive in relation to foraging, or that a worse climate had the same effect (see section 1). We are not aware of convincing evidence for the existence of such biases. Moreover, theories that appeal directly to climate biases raise further puzzles. If good climate leads to cultivation, then cultivation should have been observed during the initial warming in southwest Asia, not during the Younger Dryas. If bad climate leads to cultivation, then cultivation should have evolved during the Ice Age.

Our formal analysis was carried out on the assumption that climate changes are neutral with respect to the choice between foraging and agriculture. The migration channel in our theory removes the need for a direct bias, and provides additional empirical content by explaining which sites made the transition first within a region. Our theory gets the timing right because it is not a specific climate state that determines the outcome; instead, it is the sequence of climate events.

Our model can, however, be modified to incorporate biased climate effects. If bad climate reduced the productivity of foraging relative to cultivation, then it decreased the threshold population density for cultivation $\left(\mathrm{n}^{\mathrm{a}}\right)$, making cultivation more likely in the climate reversal. On the reasonable assumption that good climate and good location had parallel effects, this implies that better sites had higher population thresholds for cultivation, which runs counter to the observation that the transition occurred first at the sites with the best local environments. This makes our mechanism for generating local population spikes even more essential. Conversely, if good climate favored cultivation, 
one can see why cultivation would arise first at the best sites, but then it becomes harder to understand why cultivation did not arise during the initial warming phase and instead had to await the Younger Dryas.

Heterogeneity and migration. Other theories of the agricultural transition rarely distinguish between the regional and local levels. In our view, this distinction is critical. Regionally, the Younger Dryas led to greater nomadism, higher mortality, and lower food consumption in southwest Asia. This was compatible with continued sedentism, increased population, and reliance on cultivation at local refuges such as Abu Hureyra. Economic models that do not include migration among heterogeneous locations ignore the vital role of scarce refuge sites as agricultural incubators.

To see the importance of this factor, it suffices to consider a counterfactual. If all sites in southwest Asia had been identical, the Younger Dryas would not have triggered any migration among local sites, there would have been no short run spike in local population anywhere, and there would have been no transition to agriculture.

Population and technology. In recent decades there has been considerable debate as to whether climate, population, or technology should be regarded as the fundamental factor behind the emergence of agriculture. Although we see climate as the underlying exogenous variable, population and technology cannot be ignored. Without a large regional population, a climate reversal cannot create a local population density sufficient to trigger cultivation. Without rapid technical change once cultivation gets underway, falling regional population during the reversal will take society back to foraging rather than forward to a farming economy. By endogenizing population and technology, our model helps to clarify these crucial interactions. 


\section{Appendix: Proof of Proposition in Section 4}

Proposition. If A6 holds and $\mathrm{N}$ is fixed, an increase in c decreases population density $\mathrm{n}[\mathrm{Y}(\mathrm{N}, \mathrm{c}), \mathrm{c}, 1]$ at the best sites.

Proof. Let the initial climate be $c_{0}$ and let the new climate be $c_{1}>c_{0}$. Let the associated per capita incomes be $y_{0}$ and $y_{1}$ where from the short run equilibrium condition (4) in the text, these are the unique solutions to $\mathrm{N}=\int_{0}{ }^{1} \mathrm{n}\left(\mathrm{y}_{0}, \mathrm{c}_{0}, \mathrm{~s}\right) \mathrm{q}(\mathrm{s}) \mathrm{ds}=\int_{0}{ }^{1} \mathrm{n}\left(\mathrm{y}_{1}, \mathrm{c}_{1}, \mathrm{~s}\right) \mathrm{q}(\mathrm{s}) \mathrm{ds}$. We need to show that $n\left[Y\left(N, c_{0}\right), c_{0}, 1\right]>n\left[Y\left(N, c_{1}\right), c_{1}, 1\right]$ or simply $n\left(y_{0}, c_{0}, 1\right)>n\left(y_{1}, c_{1}, 1\right)$.

Recall from section 4 of the text that we have

$\underline{\text { A3 }}$

$$
\mathrm{F}\left(\mathrm{n}_{\mathrm{f}}, \mathrm{c}, \mathrm{s}\right)=\mathrm{A}(\mathrm{c}, \mathrm{s}) \mathrm{f}\left(\mathrm{n}_{\mathrm{f}}\right) \quad \text { and } \quad \mathrm{G}\left(\mathrm{n}_{\mathrm{g}}, \mathrm{c}, \mathrm{s}\right)=\mathrm{kA}(\mathrm{c}, \mathrm{s}) \mathrm{g}\left(\mathrm{n}_{\mathrm{g}}\right)
$$

This gives $\mathrm{y}(\mathrm{n}, \mathrm{c}, \mathrm{s})=A(\mathrm{c}, \mathrm{s}) \mathrm{Z}(\mathrm{n})$ where $\mathrm{Z}(\mathrm{n}) \equiv(1 / \mathrm{n})\left\{\max \mathrm{f}\left(\mathrm{n}_{\mathrm{f}}\right)+\operatorname{kg}\left(\mathrm{n}_{\mathrm{g}}\right)\right.$ subject to $\mathrm{n}_{\mathrm{f}} \geq 0, \mathrm{n}_{\mathrm{g}}$ $\geq 0$, and $\left.n_{f}+n_{g}=n\right\}$. Since $n(y, c, s)$ is the inverse of $y(n, c, s)$ for fixed $(c, s)$, we have $y_{0} \equiv$ $\mathrm{A}\left(\mathrm{c}_{0}, 1\right) \mathrm{Z}\left[\mathrm{n}\left(\mathrm{y}_{0}, \mathrm{c}_{0}, 1\right)\right]$ and $\mathrm{y}_{1} \equiv \mathrm{A}\left(\mathrm{c}_{1}, 1\right) \mathrm{Z}\left[\mathrm{n}\left(\mathrm{y}_{1}, \mathrm{c}_{1}, 1\right)\right]$. Because $\mathrm{Z}$ is decreasing, $\mathrm{n}\left(\mathrm{y}_{0}, \mathrm{c}_{0}, 1\right)>$ $\mathrm{n}\left(\mathrm{y}_{1}, \mathrm{c}_{1}, 1\right)$ holds iff $\mathrm{y}_{0} / \mathrm{A}\left(\mathrm{c}_{0}, 1\right)<\mathrm{y}_{1} / \mathrm{A}\left(\mathrm{c}_{1}, 1\right)$. Write $\mathrm{y}_{1} \equiv \mathrm{Y}\left(\mathrm{N}, \mathrm{c}_{1}\right) \equiv \theta \mathrm{Y}\left(\mathrm{N}, \mathrm{c}_{0}\right) \equiv \theta \mathrm{y}_{0}$ where $\theta$ $>1$ because $c_{1}>c_{0}$ and $Y$ is increasing in $c$ for any fixed $N$. Now suppose $A\left(c_{1}, s\right) / A\left(c_{0}, s\right)$ is decreasing in s (this will be proven below). We will show that this condition implies $\mathrm{A}\left(\mathrm{c}_{1}, 1\right)<\theta \mathrm{A}\left(\mathrm{c}_{0}, 1\right)$, which gives $\mathrm{y}_{0} / \mathrm{A}\left(\mathrm{c}_{0}, 1\right)<\mathrm{y}_{1} / \mathrm{A}\left(\mathrm{c}_{1}, 1\right)$ and hence $\mathrm{n}\left(\mathrm{y}_{0}, \mathrm{c}_{0}, 1\right)>\mathrm{n}\left(\mathrm{y}_{1}, \mathrm{c}_{1}, 1\right)$.

Suppose instead that $A\left(c_{1}, s\right) / A\left(c_{0}, s\right)$ is decreasing in $s$ but $A\left(c_{1}, 1\right) \geq \theta A\left(c_{0}, 1\right)$. This gives $\mathrm{A}\left(\mathrm{c}_{1}, \mathrm{~s}\right) / \mathrm{A}\left(\mathrm{c}_{0}, \mathrm{~s}\right)>\theta$ for all $\mathrm{s}<1$ and therefore $\mathrm{y}_{0} / \mathrm{A}\left(\mathrm{c}_{0}, \mathrm{~s}\right)>\mathrm{y}_{1} / \mathrm{A}\left(\mathrm{c}_{1}, \mathrm{~s}\right)$ for all $\mathrm{s}<$ 1. It follows that $\mathrm{y}_{0} / \mathrm{A}\left(\mathrm{c}_{0}, \mathrm{~s}\right)=\mathrm{Z}\left[\mathrm{n}\left(\mathrm{y}_{0}, \mathrm{c}_{0}, \mathrm{~s}\right)\right]>\mathrm{Z}\left[\mathrm{n}\left(\mathrm{y}_{1}, \mathrm{c}_{1}, \mathrm{~s}\right)\right]=\mathrm{y}_{1} / \mathrm{A}\left(\mathrm{c}_{1} \mathrm{~s}\right)$ for all $\mathrm{s}<1$, which implies $\mathrm{n}\left(\mathrm{y}_{0}, \mathrm{c}_{0}, \mathrm{~s}\right)<\mathrm{n}\left(\mathrm{y}_{1}, \mathrm{c}_{1}, \mathrm{~s}\right)$ for all $\mathrm{s}<1$. But then the short run equilibrium condition 
(4) in the text gives $\mathrm{N}=\int_{0}^{1} \mathrm{n}\left(\mathrm{y}_{0}, \mathrm{c}_{0}, \mathrm{~s}\right) \mathrm{q}(\mathrm{s}) \mathrm{ds}<\int_{0}^{1} \mathrm{n}\left(\mathrm{y}_{1}, \mathrm{c}_{1}, \mathrm{~s}\right) \mathrm{q}(\mathrm{s}) \mathrm{ds}=\mathrm{N}$. This contradiction shows that if $\mathrm{A}\left(\mathrm{c}_{1}, \mathrm{~s}\right) / \mathrm{A}\left(\mathrm{c}_{0}, \mathrm{~s}\right)$ is decreasing in $\mathrm{s}$ then $\mathrm{n}\left(\mathrm{y}_{0}, \mathrm{c}_{0}, 1\right)>\mathrm{n}\left(\mathrm{y}_{1}, \mathrm{c}_{1}, 1\right)$ as required.

Thus, it is sufficient to show that $\mathrm{A}\left(\mathrm{c}_{1}, \mathrm{~s}\right) / \mathrm{A}\left(\mathrm{c}_{0}, \mathrm{~s}\right)$ is decreasing in $\mathrm{s}$. Differentiating with respect to $\mathrm{s}$, this is true if (i) $\mathrm{A}\left(\mathrm{c}_{0}, \mathrm{~s}\right) / \mathrm{A}_{\mathrm{s}}\left(\mathrm{c}_{0}, \mathrm{~s}\right)<\mathrm{A}\left(\mathrm{c}_{1}, \mathrm{~s}\right) / \mathrm{A}_{\mathrm{s}}\left(\mathrm{c}_{1}, \mathrm{~s}\right)$ for all $\mathrm{s}$. In turn, (i) is true if (ii) $\mathrm{A}(\mathrm{c}, \mathrm{s}) / \mathrm{A}_{\mathrm{s}}(\mathrm{c}, \mathrm{s})$ is increasing in $\mathrm{c}$ at each $\mathrm{s}$. Differentiating with respect to $\mathrm{c}$, (ii) is true if (iii) $A_{c}(c, s) A_{s}(c, s)>A(c, s) A_{c s}(c, s)$ for all $(c, s)$. In the rest of the proof we show that (iii) holds if $\mathrm{A}(\mathrm{c}, \mathrm{s})$ has constant returns to scale and elasticity of substitution $\sigma>1$, as assumed in A6 from section 4 of the text.

Consider the expenditure minimization problem

$$
\min \mathrm{p}_{\mathrm{s}} \mathrm{s}+\mathrm{p}_{\mathrm{c}} \mathrm{c} \quad \text { subject to } \mathrm{A}(\mathrm{c}, \mathrm{s})=\mathrm{A}^{0} \text {. }
$$

Define $\mathrm{p} \equiv \mathrm{p}_{\mathrm{s}} / \mathrm{p}_{\mathrm{c}}$. From the first order conditions we have $\mathrm{pA}_{\mathrm{c}}[\mathrm{c}(\mathrm{p}), \mathrm{s}(\mathrm{p})] \equiv \mathrm{A}_{\mathrm{s}}[\mathrm{c}(\mathrm{p}), \mathrm{s}(\mathrm{p})]$ and $A[c(p), s(p)] \equiv A^{0}$. The elasticity of substitution is $\sigma=-d[s(p) / c(p)] / d p \bullet p /[s(p) / c(p)]$ $=-\left[\left(\mathrm{s}^{\prime} / \mathrm{s}\right)-\left(\mathrm{c}^{\prime} / \mathrm{c}\right)\right] \mathrm{p}$. Differentiating the identities that define $\mathrm{s}(\mathrm{p})$ and $\mathrm{c}(\mathrm{p})$ gives $\mathrm{c}^{\prime}(\mathrm{p})=$ $A_{c} /\left[2 A_{c s}-\left(A_{s s} A_{c} / A_{s}\right)-\left(A_{c c} A_{s} / A_{c}\right)\right]$ and $s^{\prime}(p)=-A_{c} c^{\prime} / A_{s}$. Substituting these results into the expression for $\sigma$ shows that $\sigma>1$ iff $A_{c} / s+A_{s} / c>2 A_{c s}-\left(A_{s s} A_{c} / A_{s}\right)-\left(A_{c c} A_{s} / A_{c}\right)$. From constant returns, the marginal products $A_{c}$ and $A_{s}$ are homogeneous of degree zero. This gives $\mathrm{A}_{\mathrm{cc}}=-\mathrm{A}_{\mathrm{cs}} \mathrm{s} / \mathrm{c}$ and $\mathrm{A}_{\mathrm{ss}}=-\mathrm{A}_{\mathrm{cs}} \mathrm{c} / \mathrm{s}$. Substituting in the preceding inequality shows that $\sigma>1$ iff $\mathrm{A}_{\mathrm{c}} \mathrm{A}_{\mathrm{s}}>\left(\mathrm{cA}_{\mathrm{c}}+\mathrm{sA}_{\mathrm{s}}\right) \mathrm{A}_{\mathrm{cs}}=\mathrm{AA}_{\mathrm{cs}}$ where the equality follows from constant returns. This establishes condition (iii) in the preceding paragraph and completes the proof. 


\section{References}

Ashraf, Quamrul and Stelios Michalopoulos, 2006, The climatic origins of the Neolithic revolution: A theory of long-run development via climate-induced technological progress, working paper, Department of Economics, Brown University.

Baker, Matthew J., 2007, A structural model of the Neolithic revolution, working paper, Department of Economics, Hunter College, City University of New York.

Balter, Michael, 2007, Seeking agriculture's ancient roots, Science 316 (June 29), 183035.

Bar-Yosef, Ofer, 2002a, The Natufian culture and the early Neolithic: Social and economic trends in Southwestern Asia, in P. Bellwood and C. Renfrew, eds., Examining the Farming/Language Dispersal Hypothesis, McDonald Institute Monographs, University of Cambridge, Cambridge, 113-26.

Bar-Yosef, Ofer, 2002b, Natufian, in B. Fitzhugh and J. Habu, eds., Beyond Foraging and Collecting: Evolutionary Change in Hunter-Gatherer Settlement Systems, Kluwer Academic/Plenum Publishers, New York, 91-149.

Bar-Yosef, Ofer and Richard H. Meadow, 1995, The origins of agriculture in the near east, Ch. 3 in T. Douglas Price and Anne Birgitte Gebauer, eds., Last Hunters, First Farmers: New Perspectives on the Prehistoric Transition to Agriculture, School of American Research Press, Santa Fe, New Mexico, 39-94.

Becker, Gary, Edward Glaeser, and Kevin Murphy, 1999, Population and economic growth, American Economic Review 89(2), May, 145-9.

Bellwood, Peter, 2005, First Farmers: The Origins of Agricultural Societies, Blackwell, Oxford. 
Bockstette, Valerie, Areendam Chandra, and Louis Putterman, 2002, States and markets:

The advantage of an early start, Journal of Economic Growth 7(4), December, 34769.

Campbell, Bernard G., James D. Loy, and Kathryn Cruz-Uribe, 2006, Humankind Emerging, Pearson, New York.

Childe, V. Gordon, 1951, Man Makes Himself, New American Library, New York.

Colledge, Sue M., 1998, Identifying pre-domestication cultivation using multivariate analysis, in A.B. Damania, J. Valkoun, G.H. Wilcox, and C.O. Qualset, eds., The Origins of Agriculture and Crop Domestication, Aleppo, Syria: ICARDA, 121-31. Colledge, Sue M., 2002, Identifying pre-domestication cultivation in the archaeobotanical record using multivariate analysis: Presenting the case for quantification, in R. Cappers, S. Bottema, and U. Baruch, eds., The Transition from Foraging to Farming in Southwest Asia, Berlin, ex orient. 141-52.

Cronin, Thomas M., 1999, Principles of Paleoclimatology, Columbia University Press, New York.

Deur, Douglas, 1999, Salmon, sedentism, and cultivation: Toward an environmental prehistory of the northwest coast, Ch. 7 in P. Hirt and D. Goble, eds., Northwest Lands and Peoples: An Environmental History Anthology, University of Washington Press, Seattle, 119-44.

Deur, Douglas, 2002, Plant cultivation on the northwest coast: A reconsideration, Journal of Cultural Geography 19(2), Spring/Summer, 9-35.

Diamond, Jared, 1997, Guns, Germs, and Steel: The Fate of Human Societies, Norton, New York. 
Dillehay, Tom, Jack Rossen, Thomas Andres, and David Williams, 2007, Preceramic adoption of peanut, squash, and cotton in northern Peru, Science 316, June 29, 1890-3.

Dow, Gregory K., Nancy Olewiler, and Clyde G. Reed, 2005, The transition to agriculture: Climate reversals, population density, and technical change, available at http://ideas.repec.org/p/wpa/wuwpeh/0509003.html

Dow, Gregory K. and Clyde G. Reed, 2008, Why did progress take so long? Stagnation and innovation before agriculture, working paper, Department of Economics, Simon Fraser University.

Flannery, Kent V., 1986, Guila Naquitz, Academic Press, New York.

Galor, Oded, 2005, From stagnation to growth: Unified growth theory, ch. 4 in $\underline{\text { Handbook }}$ of Economic Growth, Philippe Aghion and Steven Durlauf, eds., available at http://econpapers.repec.org/bookchap/eeegrochp/

Galor, Oded and David Weil, 2000, Population, technology, and growth: From Malthusian stagnation to the demographic transition and beyond, American Economic Review 90(4), September, 806-28.

Goebel, Ted, Michael R. Waters, and Dennis H. O'Rourke, 2008, The late Pleistocene dispersal of modern humans in the Americas, Science 319, March 14, 1497-502.

Habu, Junko, 2004, Ancient Jomon of Japan, Cambridge University Press, Cambridge. Harlan, Jack R., 1995, The Living Fields: Our Agricultural Heritage, Cambridge University Press, Cambridge.

Higham, Charles, 1995, The transition to rice cultivation in southeast Asia, Ch. 5 in T. Douglas Price and Anne Birgitte Gebauer, eds., Last Hunters, First Farmers: New 
Perspectives on the Prehistoric Transition to Agriculture, School of American Research Press, Santa Fe, New Mexico, 127-55.

Hillman, Gordon C. and M. Stuart Davies, 1990, Measured domestication rates in wild wheats and barley under primitive cultivation, and their archaeological implications, Journal of World Prehistory 4(2), 157-222.

Hillman, Gordon, Robert Hedges, Andrew Moore, Susan Colledge, and Paul Pettitt, 2001, New evidence of lateglacial cereal cultivation at Abu Hureyra on the Euphrates, The Holocene 11(4), 383-93.

Johnson, Allen W. and Timothy Earle, 2000, The Evolution of Human Societies: From Foraging Band to Agrarian State, $2^{\text {nd }}$ ed., Stanford University Press, Stanford.

Keeley, Lawrence H., 1995, Protoagricultural practices among hunter-gatherers: A crosscultural survey, Ch. 9 in T. Douglas Price and Anne Birgitte Gebauer, eds., Last Hunters, First Farmers: New Perspectives on the Prehistoric Transition to Agriculture, School of American Research Press, Sante Fe, New Mexico, 243-72.

Kelly, Robert I., 1995, The Foraging Spectrum: Diversity in Hunter-Gatherer Lifeways, Smithsonian Institution Press, Washington, D.C.

Kremer, Michael, 1993, Population growth and technological change: One million B.C. to 1990, Quarterly Journal of Economics 108(3), August, 681-716.

Locay, Luis, 1989, From hunting and gathering to agriculture, Economic Development and Cultural Change, 37(4), July, 737-56.

Locay, Luis, 1997, Population equilibrium in primitive societies, Quarterly Review of Economics and Finance 37(4), Fall, 747-67. 
Lu, Tracey Lie Dan, 1999, The Transition from Foraging to Farming and the Origin of Agriculture in China, BAR International Series 774, Hadrian Books, Oxford.

Marcus, J. and Kent V. Flannery, 1996, Zapotec Civilization: How Urban Society Evolved in Mexico's Oaxaca Valley, Thames \& Hudson, London.

Matsuoka, Y., Y. Vigouroux, M. Goodman, J. Sanchez, E. Buckler, and J. Doebley, 2002, A single domestication for maize shown by multilocus microsatellite genotyping, Proceedings of the National Academy of Sciences USA 99(9), 6080-4.

McDougall, I., F. H. Brown, and J. G. Fleagle, 2005, Stratigraphic placement and age of modern humans from Kibish, Ethiopia, Nature 433, February 17, 733-6.

McManus, Jerry F., 2004, Palaeoclimate: A great grand-daddy of ice cores, Nature 429, June 10,611-2.

Mithen, Steven, 2003, After the Ice: A Global Human History, 20,000 - 5000 BC, Weidenfeld \& Nicolson, London.

Moore, A.M.T., G.C. Hillman, and A.J. Legge, 2000, Village on the Euphrates: From Foraging to Farming at Abu Hureyra, Oxford University Press, Oxford.

Morand, Olivier, 2002, Evolution through revolutions: Growing populations and changes in modes of production, working paper, Department of Economics, University of Connecticut.

National Research Council, 2002, Abrupt Climate Change, National Research Council Committee on Abrupt Climate Change, Washington, D.C.

Nesbitt, Mark, 2002, When and where did domesticated cereals first occur in southwest Asia?, in R. Cappers, S. Bottema, and U. Baruch, eds., The Transition from Foraging to Farming in Southwest Asia, Berlin, ex orient. 113-32. 
Olsson, Ola, 2001, The rise of Neolithic agriculture, working paper in economics 57, Department of Economics, Goteborg University.

Olsson, Ola and Douglas A. Hibbs, Jr., 2005, Biogeography and long-run economic development, European Economic Review 49(4), May, 909-38.

Piperno, D.R., J.E. Moreno, J. Iriarte, I. Holst, M. Lachniet, J.G. Jones, A.J. Ranere and R. Castanzo, 2007, Late Pleistocene and Holocene environmental history of the Iguala Valley, Central Balsas watershed of Mexico, Proceedings of the National Academy of Sciences USA, online edition, available at www.pnas.org/cgi/doi/10.1073/pnas.0703442104

Pryor, Frederic, 1983, Causal theories about the origins of agriculture, Research in Economic History 8, 93-124.

Pryor, Frederic, 1986, The adoption of agriculture: Some theoretical and empirical evidence, American Anthropologist 88(4), December, 879-97.

Pryor, Frederic, 2004, From foraging to farming: The so-called "Neolithic Revolution", in Alexander J. Field, ed., Research in Economic History 22, JAI Press, 1-41.

Putterman, Louis, 2008, Agriculture, diffusion and development: Ripple effects of the Neolithic revolution, Economica, online publication January 4.

Richerson, Peter J., Robert Boyd, and Robert L. Bettinger, 2001, Was agriculture impossible during the Pleistocene but mandatory during the Holocene? A climate change hypothesis, American Antiquity 66(3), July, 387-411.

Sandweiss, D. H., K. A. Maasch, and D. G. Anderson, 1999, Transitions in the midHolocene, Science 283, January 22, 499-500. 
Smith, Bruce D., 1998, The Emergence of Agriculture, Scientific American Library, New York.

Smith, Bruce D., 2001, Documenting plant domestication: The consilience of biological and archaeological approaches, Proceedings of the National Academy of Sciences 98(4), February 13, 1324-6.

Tanno, Ken-ichi and George Wilcox, 2006, How fast was wild wheat domesticated? Science 311, March 31, 1886.

Weisdorf, Jacob L., 2005, From foraging to farming: Explaining the Neolithic revolution, Journal of Economic Surveys 19(4), September, 561-86.

Weiss, Ehud, Mordechai E. Kislev, and Anat Harmann, 2006, Autonomous cultivation before domestication, Science 312, June 16, 1608-10.

Weiss, Ehud, Wilma Wetterstrom, Dani Nadel, Ofer Bar-Yosef, and Bruce D. Smith, 2004, The broad spectrum revisited: Evidence from plant remains, Proceedings of the National Academy of Sciences 101(26), June 29, 9551-5.

Wolff, Eric, et al., 2004, Eight glacial cycles from an Antarctic ice core, Nature 429, June $10,623-8$.

Wright, Herbert E. Jr. and Joanna Thorpe, 2003, Climatic change and the origin of agriculture in the Near East, in Anson W. Mackay, Richard W. Battarbee, H. John Birks, and Frank Oldfield, eds., Global Change in the Holocene, Hodder Arnold, London, 49-62. 


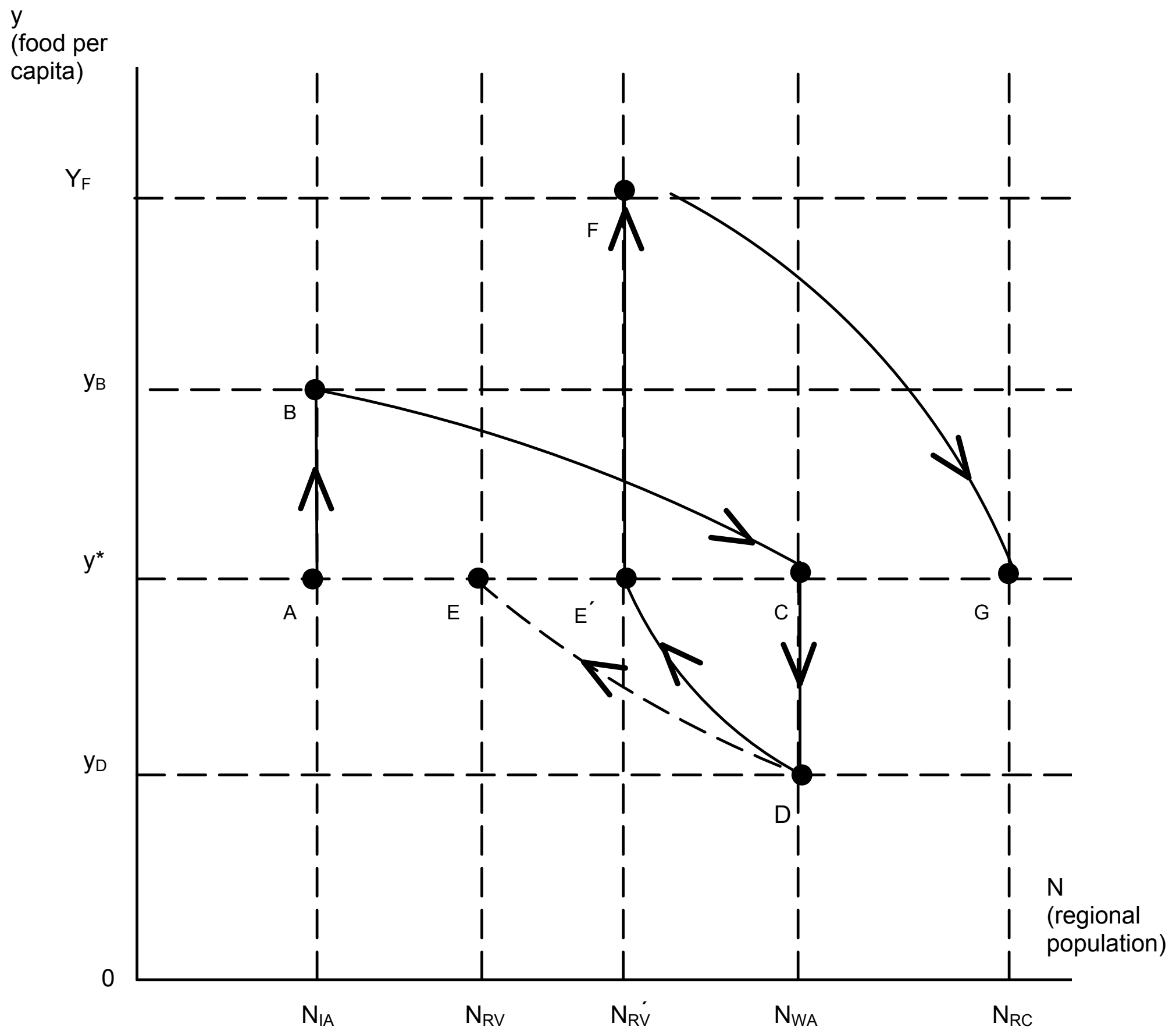

Figure 1

Dynamics of Regional Population and

Food per Capita 
$\mathrm{n}_{1 \mathrm{t}}$

(population at best sites)

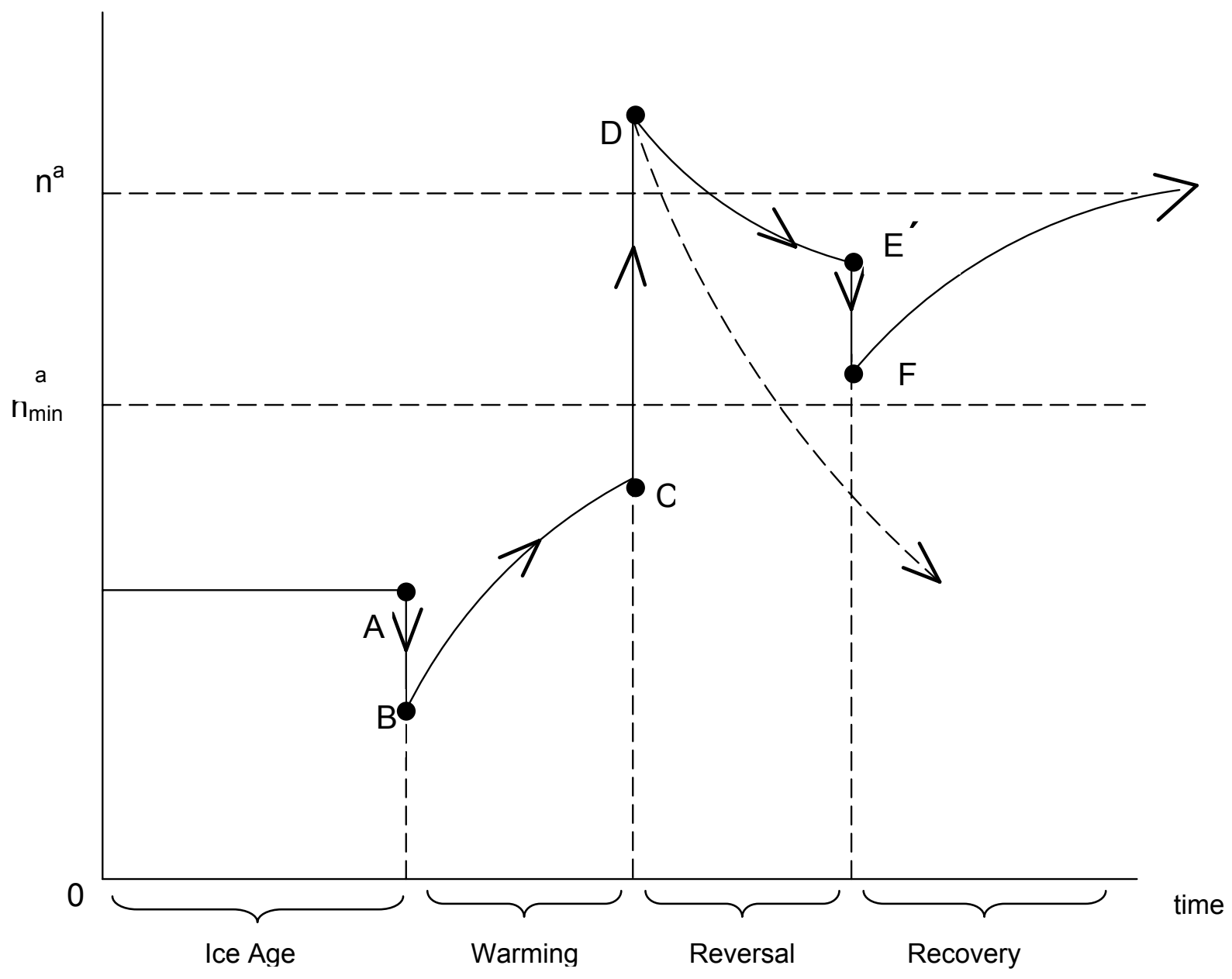

Figure 2

Population Density At The Best Sites 
k

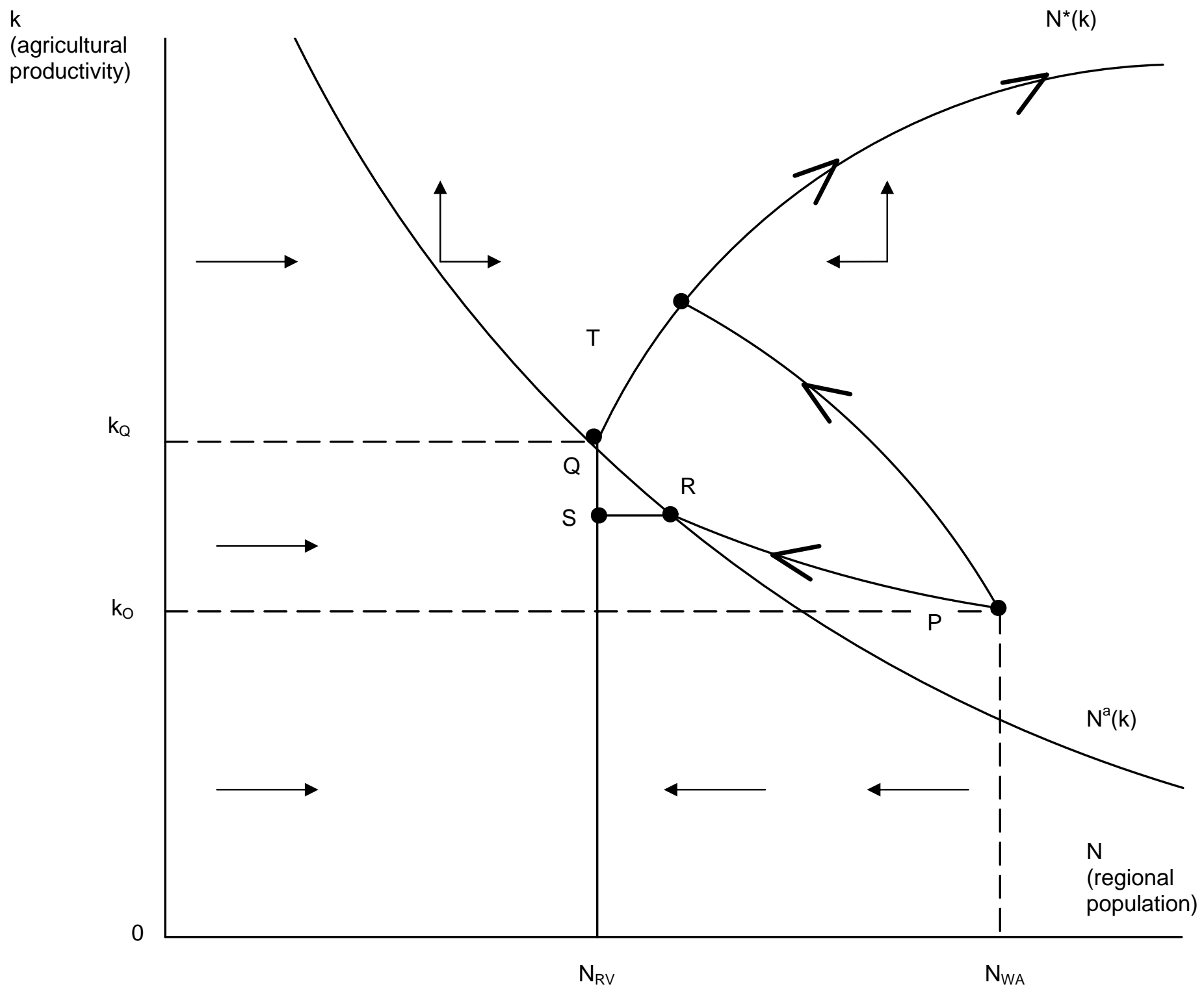

productivity)

Figure 3

Dynamics of Population and

Technology During A Climate Reversal 